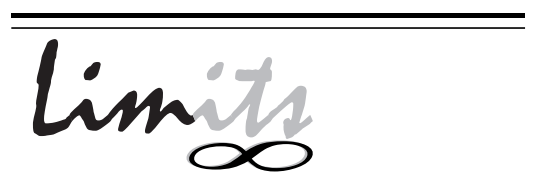

J. Math. and Its Appl.

ISSN : $1829-605 \mathrm{X}$

Vol. 4, No. 2, November 2007, 53-64

\title{
WAVELET-JARINGAN SYARAF TIRUAN UNTUK PREDIKSI DATA TIME SERIES
}

\author{
Daryono Budi Utomo \\ Jurusan Matematika \\ FMIPA Institut Teknologi Sepuluh Nopember, Surabaya \\ daryono@matematika.its.ac.id
}

\begin{abstract}
Abstrak
Prediksi data time series dapat digunakan sebagai bahan pertimbangan dalam pengambilan keputusan yang akan datang. Jaringan syaraf tiruan merupakan metoda yang baik untuk memprediksi data time series, akan tetapi sulit dihindari adanya epoch (iterasi) yang banyak selama pelatihan. Sedangkan wavelet dapat dipakai untuk mendekomposisi dan merekontruksi data sehingga dapat mengurangi banyaknya epoch. Pada makalah ini, dibahas bagaimana WaveletJaringan Syaraf Tiruan, yang selanjutnya disebut WANN (WaveletArtificial Neural Network) digunakan untuk memprediksi data time series.

Ada tiga tahapan untuk mendapatkan hasil prediksi data times series dengan metoda WANN, yaitu pre-processing, prediction, dan post-processing. Pre-processing digunakan untuk mendekomposisi data masukan, prediction merupakan proses training, dan post processing dipakai untuk merekontruksi data setelah dilakukan training. Selanjutnya dilakukan simulasi dengan menggunakan MATLAB. Dari simulasi ini diperoleh data short term prediction dan long term prediction. Katakunci: Jaringan syaraf tiruan, pre-processing, prediction, postprocessing, wavelet
\end{abstract}




\section{Pendahuluan}

Prediksi data time series banyak digunakan sebagai bahan pertimbangan untuk proses pengambilan keputusan, untuk itu keakuratan dalam memprediksi data memegang peranan penting agar keputusan yang diambil dapat dipertanggung jawabkan. Sebagai contoh, berapa mega watt daya listrik yang harus disediakan untuk daerah Surabaya lima tahun mendatang ? Berdasarkan data sebelumnya dapat ditentukan perkiraan kebutuhan daya listrik lima tahun mendatang, dari hasil prediksi ini dapat diambil keputusan dalam membangun jaringan listrik maupun penyediaan sumber daya listrik serta beaya yang dibutuhkan.

Ide penggunaan jaringan syaraf tiruan untuk prediksi data telah ditulis oleh [7]. Prediksi data dengan menggunakan Kalman Filter dan transformasi wavelet dilakukan oleh [6]. [4] melakukan penelitian tentang data time series untuk memprediksi stok market dengan menggunakan jaringan syaraf tiruan. [8] melakukan penelitian untuk menentukan kosentrasi NOx dan NO2 pada polusi udara dengan meng-gunakan metoda wavelet-jaringan syaraf tiruan. Prediksi data time series dengan menggunakan metoda gabungan wavelet dan jaringan syaraf tiruan untuk daya Listrik dilakukan [5]

Pada makalah ini akan dibahas prediksi data time series dengan menggunakan metoda Wavelet-Jaringan Syaraf Tiruan yang selanjutnya dinamakan WANN. Simulasi program ditulis dengan memanfaatkan modulmodul fungsi yang ada pada MATLAB, data aktual yang digunakan adalah data harian kurs jual-beli Rupiah terhadap dollar Amerika yang diambil dari Bank Indonesia. Untuk mengukur keakuratan hasil prediksi data digunakan Mean Absolute Percentage Error (MAPE). Model dari Jaringan syaraf Tiruan yang digunakan adalah Back Propagation satu layer. Jumlah neuron hidden yang digunakan adalah 1, 2, 3 dan 4 node, banyaknya prediktor adalah 2, 3 dan 4 data.

\section{Pembahasan}

\section{Prediksi Data Time Series dan Wavelet}

Dalam memprediksi data terdapat dua metode prediksi yaitu metode kualitatif (subjektif) dan metode kuantitatif. Metode prediksi kualitatif 
lebih mengandalkan pendapat (judgment) dan intuisi manusia dari pada penggunaan data historis yang dimiliki[2]. Sedangkan metode prediksi kuantitif dapat diterapkan apabila terdapat tiga kondisi berikut :

1. Tersedianya informasi tentang masa lalu,

2. Informasi tersebut dapat dikuantitatifkan dalam bentuk data numerik,

3. Diasumsikan bahwa beberapa aspek pola masa lalu akan terus berlanjut dimasa mendatang.

Tujuan dari metode prediksi data time series adalah menemukan pola dalam data time series dan mengekstrapolasikan pola tersebut ke masa depan. Prosedur untuk menemukan data prediksi untuk data times series digunakan metode moving windows artinya untuk mencari data prediksi ke- $n$ digunakan data $(n-1),(n-2), \cdots$ yang disebut sebagai prediktor. Dalam prediksi data time series terdapat dua bentuk prediksi yaitu short term prediction dan long term prediction. Short term prediction artinya untuk menemukan data prediksi menggunakan beberapa data masa lalu, sedangkan long term prediction berdasarkan data dimasa lalu dan melibatkan data hasil prediksi pada short term prediction.

Pada makalah ini, dibahas bagaimana WANN digunakan untuk memprediksi data time series. Fungsi skala $\phi$ dalam wavelet yang digunakan dalam makalah ini adalah fungsi skala Haar, didefinisikan oleh [1]:

$$
\phi(x)=\left\{\begin{array}{ccc}
1 & ; \text { jika } & 0 \leq x \leq 1 \\
0 & ; \text { jika } & \text { lainnya }
\end{array} .\right.
$$

Fungsi wavelet $\psi$ didefinisikan oleh :

$$
\psi(x)=\sum_{k \in Z}(-1)^{k} p_{1-k} \phi(2-k)
$$

untuk $z=\{0,1\}$ dan $k=1$ didapat wavelet Haar: $\psi(x)=\phi(2 x)-\phi(2 x-1)$.

Sedangkan fungsi aktivasi yang digunakan pada jaringan syaraf tiruan adalah fungsi biner yang dinyatakan sebagai berikut:

$$
f(x)=\left\{\begin{array}{lll}
1 & ; \text { untuk } \quad \theta \geq 0 \\
0 & ; \text { untuk } \quad \theta<0
\end{array} \text { dan } \theta=\right.\text { threshold }
$$


Metode untuk menghitung jaringan input digunakan perkalian matriks. Jika bobot koneksi untuk neural net disimpan pada matriks $W=\left(w_{i j}\right)$ dan input vektor $x_{i}$ maka:

$$
y_{\_} i n_{j}=\sum_{i=1}^{n} x_{i} w_{i j}
$$

Bias disertakan sebagai input dengan cara menambahkan komponen $x_{0}=1$, faktor bias diperlukan untuk training dan input bias selalu satu. Jika bobot bias dinyatakan dengan $b_{j}$ maka :

$$
y_{-} i n_{j}=b_{j}+\sum_{i=1}^{n} x_{i} w_{i j}
$$

\section{Back Propagation}

Metode Back Propagation adalah metode gradient descent untuk meminimalkan total mean square error (MSE) dari output yang dihitung oleh jaringan. Training jaringan dengan back propagation meliputi tiga tahap sebagai berikut :

1. Feed forward dari pola input training.

2. Perhitungan error propagasi balik (backpropagation of error).

3. Pembaharuan (adjustment) bobot dan bias.

Setelah proses training, aplikasi jaringan hanya meliputi perhitungan feed forward. Arsitektur jaringan syaraf tiruan dari back propagation merupakan jaringan multi-layer. Pada unit input dan unit hidden ditambah satu node bias yang mempunyai bobot yang selalu bernilai satu. Bias pada unit output $Y_{k}$ dilambangkan dengan $w_{0 k}$, bias pada unit hidden $Z_{j}$ dilambangkan dengan $v_{0 j}$. Arsitektur jaringan multi-layer dengan satu layer, $p$ unit hidden (unit $Z$ ) dan satu unit output (unit $Y$ ) ditunjukkan pada Gambar 1.

\section{Algoritma training backpropagation[3]}

Step 0 : Inisialisasi nilai bobot dengan nilai acak yang kecil.

Step 1 : Selama kondisi pada step 9 tidak terpenuhi, kerjakan step 2 - 9 .

Step 2 : Untuk tiap pasangan pelatihan, kerjakan step 3-8.

\section{Feedforward :}




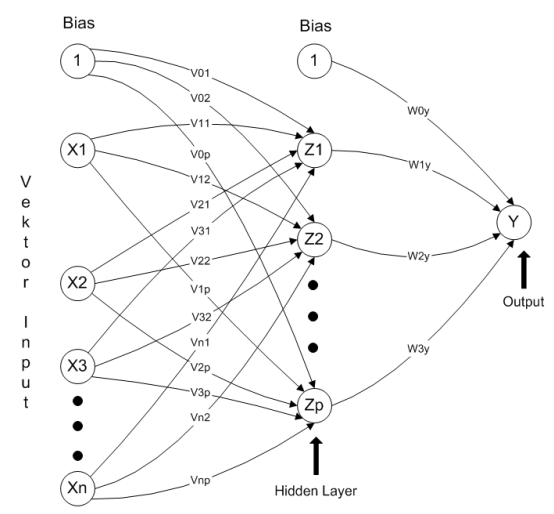

Gambar 1: Arsitektur Backpropagation dengan satu hidden layer satu output

Step 3: Untuk setiap unit input $\left(X_{i}, i=1, \ldots, n\right)$ menerima sinyal input $x_{i}$ dan menyebarkan sinyal itu keseluruh unit pada layer atasnya (hidden layer).

Step 4 : Untuk tiap unit dalam $\left(Z_{j}, j=1, \ldots, p\right)$ dihitung nilai input dengan menggunakan nilai bobotnya: $z_{\imath} i n_{j}=v_{0 j}+\sum_{i=1}^{n} x_{i} v_{i j}$. Selanjutnya dihitung nilai output dengan menggunakan fungsi aktivasi yang dipilih: $z_{j}=f\left(z_{-} i n_{j}\right)$.

Hasil fungsi tersebut dikirim ke semua unit pada layer di atasnya (unit output).

Step 5: Untuk tiap unit output $\left(Y_{k}, k=1, \ldots, m\right)$ dihitung nilai input dengan menggunakan nilai bobot-nya: $y_{-} i n_{k}=w_{0 k}+\sum_{j=1}^{p} z_{j} w_{j k}$.

Selanjutnya dihitung nilai output dengan meng-gunakan fungsi aktivasi: $y_{k}=f\left(y_{-} i n_{k}\right)$.

\section{Backpropagation Of Error :}

Step 6 : Untuk tiap unit output $\left(Y_{k}, k=1, \ldots, m\right)$ menerima pola target yang bersesuaian dengan pola input dan kemudian dihitung informasi kesalahan

$$
\delta_{k}=\left(t_{k}-y_{k}\right) f^{\prime}\left(y_{\_} i n_{k}\right)
$$

Selanjutnya dihitung koreksi nilai bobot yang kemudian akan digunakan untuk memperbaharui nilai bobot $w_{j k}: \triangle w_{j k}=\alpha \delta_{k} z_{j}$. 
Hitung koreksi nilai bias yang kemudian akan di-gunakan untuk mem-perbaharui nilai $w_{0 k}: \Delta w_{0 k}=\alpha \delta_{k}$, kemudian nilai $\delta_{k}$ dikirim ke unit pada layer sebelumnya.

Step 7 : Untuk tiap unit dalam $\left(Z_{j}, j=1, \ldots, p\right)$ dihitung delta input yang berasal dari unit pada layer di atasnya dengan menggunakan

$$
\delta_{-} i n_{j}=\sum_{k=1}^{m} \delta_{k} w_{j k}
$$

Selanjutnya nilai tersebut dikalikan dengan nilai turunan dari fungsi aktivasi untuk menghitung informasi kesalahan: $\delta_{j}=$ $\delta \_i n_{j} f^{\prime}\left(z_{\_} i n_{j}\right)$. Hitung koreksi nilai bobot yang kemudian digunakan untuk memperbaharui nilai $v_{i j}: \Delta v_{i j}=\alpha \delta_{j} x_{i}$ dan hitung nilai koreksi bias yang kemudian digunakan untuk memperbaharui $v_{0 j}: \triangle v_{0 j}=\alpha \delta_{j}$.

\section{Update nilai bobot dan bias :}

Step 8 : Tiap unit output $\left(Y_{k}, k=1, \ldots, m\right)$ mengupdate bias dan bobotnya $(j=0, \ldots, p)$

$$
w_{j k}(\text { new })=w_{j k}(\text { old })+\triangle w_{j k}
$$

Tiap unit hidden $\left(Z_{j}, j=1, \ldots, p\right)$ mengupdate bias dan bobotnya $(i=0, \ldots, n)$

$$
v_{i j}(n e w)=v_{i j}(\text { old })+\triangle v_{i j}
$$

Step 9 : Menguji apakah net kondisi sudah terpenuhi.

\section{Model prediksi}

Model prediksi data time series dan struktur program serta penggunaan fungsi-fungsi ini diperlihatkan pada Gambar 2.

Untuk mendapatkan prediksi data dari model, melalui tiga tahapan sebagai berikut

1. Pre-processing data.

2. Prediction: training di Jaringan Syaraf tiruan.

3. Untuk mengembalikan data seperti semula hasil dari training dilakukan post-processing. Hasil dari post processing ini merupakan data prediksi [5] 


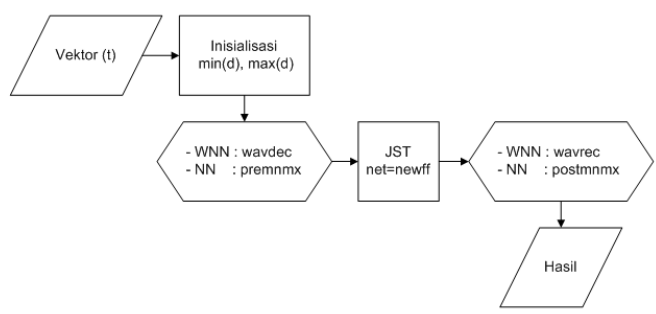

Gambar 2: Struktur Program dan Penggunaan Fungsi MATLAB

\section{Simulasi dan Uji Coba}

Dalam melakukan uji coba program, menggunakan ketentuan sebagai berikut :

- Banyak data untuk trainning dan testing : 80

- Banyak data untuk uji short dan long term prediction: 20

- Banyak neuron yang digunakan : 1, 2, 3, 4

- Banyak prediktor yang digunakan : 2, 3 dan 4 data

- Wavelet yang digunakan : Daubechies 2

Data yang digunakan adalah data kurs beli Rupiah terhadap dolar Amerika Serikat sebanyak 120 data dari tanggal 2 Januari 2006 sampai dengan 28 Juni 2006. Untuk mengukur jaringan digunakan MAPE (Mean Absolute Percentage Error) yang dinyatakan dengan :

$$
M A P E=\left[\frac{1}{N} \sum_{i=1}^{N} \frac{\left(x_{i}-y_{i}\right)}{x_{i}}\right] * 100 \%
$$

$x_{i}=$ Data aktual

$y_{i}=$ Data hasil training

$N=$ Banyak data yang di training.

\section{Hasil Uji Performance Jaringan}

Banyak data yang digunakan $n=80$, hasil performance jaringan yang diukur dengan MAPE ditunjukkan pada Tabel 1. Untuk grafik hasil uji performance ditunjukkan pada Gambar 3. 
Tabel 1: Performance Uji Jaringan

\begin{tabular}{|l|l|l|l|}
\hline NH & P & MAPE WANN & MAPE NN \\
\hline 1 & 2 & $0.1617808 \%$ & $0.3888068 \%$ \\
\hline 2 & 2 & $0.1618688 \%$ & $0.3888068 \%$ \\
\hline 3 & 2 & $0.1618388 \%$ & $0.3888068 \%$ \\
\hline 4 & 2 & $0.1618388 \%$ & $0.3888068 \%$ \\
\hline 1 & 3 & $0.1777368 \%$ & $0.5470548 \%$ \\
\hline 2 & 3 & $0.1777368 \%$ & $0.5470548 \%$ \\
\hline 3 & 3 & $0.1777368 \%$ & $0.5470548 \%$ \\
\hline 4 & 3 & $0.1777368 \%$ & $0.5470548 \%$ \\
\hline 1 & 4 & $0.1923748 \%$ & $0.8100528 \%$ \\
\hline 2 & 4 & $0.1923748 \%$ & $0.8100528 \%$ \\
\hline 3 & 4 & $0.1923748 \%$ & $0.8100528 \%$ \\
\hline 4 & 4 & $0.1923748 \%$ & $0.8100528 \%$ \\
\hline
\end{tabular}

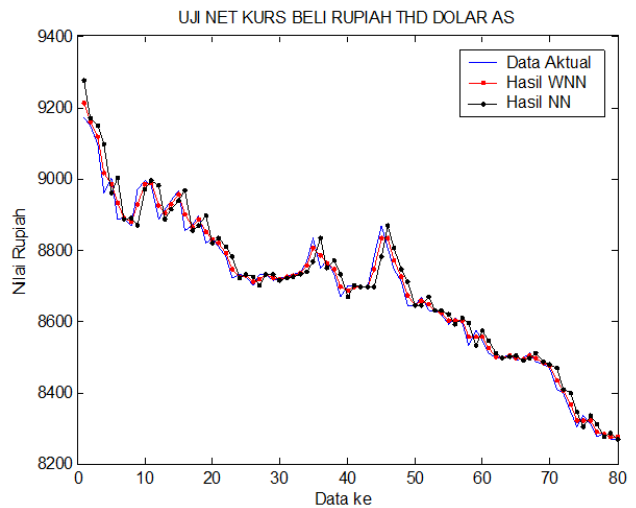

Gambar 3: Grafik Uji Performance Jaringan

Berdasarkan pada Tabel 1 hasil dari MAPE cukup kecil sehingga jaringan dapat digunakan untuk melakukan prediksi data.

\section{Hasil Prediksi Data Short Term Prediction}

Banyak data yang digunakan $n=20$, hasil performance prediksi da- 
ta yang diukur dengan MAPE ditunjukkan pada Tabel 2. Untuk grafik hasil uji performance dengan $\mathrm{NH}=1$ dan Prediktor $=2$ ditunjukkan pada Gambar 4. Berdasarkan pada Tabel 2 terlihat bahwa jika jumlah NH di-

Tabel 2: Performance short term prediction

\begin{tabular}{|l|l|l|l|}
\hline $\mathrm{NH}$ & $\mathrm{P}$ & MAPE WANN & MAPE NN \\
\hline 1 & 2 & $0.2718588 \%$ & $0.6000688 \%$ \\
\hline 2 & 2 & $0.2718498 \%$ & $0.7053498 \%$ \\
\hline 3 & 2 & $0.2718498 \%$ & $0.7664508 \%$ \\
\hline 4 & 2 & $0.2718778 \%$ & $0.6420968 \%$ \\
\hline 1 & 3 & $0.3296998 \%$ & $2.1150568 \%$ \\
\hline 2 & 3 & $0.3296998 \%$ & $2.3326358 \%$ \\
\hline 3 & 3 & $0.3296998 \%$ & $2.1081778 \%$ \\
\hline 4 & 3 & $0.3296998 \%$ & $2.6627998 \%$ \\
\hline 1 & 4 & $0.3252118 \%$ & $2.6519958 \%$ \\
\hline 2 & 4 & $0.3252118 \%$ & $3.1646888 \%$ \\
\hline 3 & 4 & $0.3252118 \%$ & $3.0351488 \%$ \\
\hline 4 & 4 & $0.3252118 \%$ & $2.9289798 \%$ \\
\hline
\end{tabular}

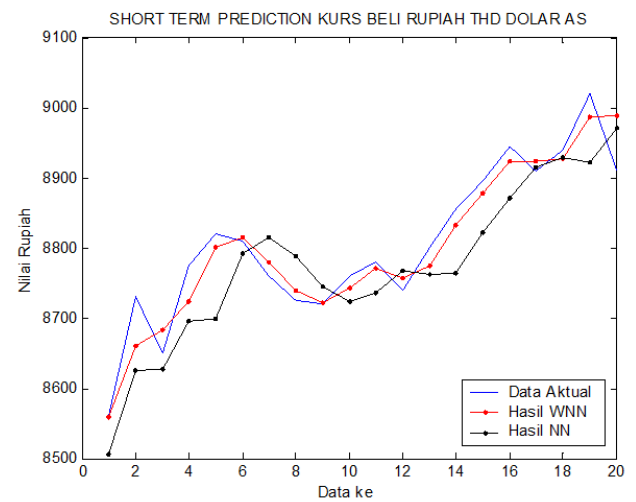

Gambar 4: Hasil Short Term Prediction NH $=1$ Prediktor $=2$ 
tambah, hasil MAPE tidak berkurang. Jadi penambahan jumlah NH tidak memperbaiki hasil prediksi data. Penambahan pada banyak prediktor hasil MAPE semakin besar, jadi penambahan jumlah predictor mengakibatkan menurun-nya hasil prediksi data. Berdasarkan grafik pada Gambar 4, hasil prediksi data WANN maupun NN sudah mengikuti tren data aktual sehingga dapat dikatakan bahwa hasil prediksi sudah sesuai.

\section{Hasil Prediksi Data Long Term Prediction}

Prediksi data ke-1 pada long term prediction masih merupakan hasil prediksi data short term prediction. Hasil prediksi data ke-2 dan seterusnya merupakan hasil dari long term prediction. Performance untuk long term prediction diperlihatkan pada Tabel 3 dan tampilan grafik untuk hasil dapat dilihat pada Gambar 5.

Tabel 3: Performance Long Term Prediction dengan $n=20$

\begin{tabular}{|l|l|l|l|}
\hline $\mathrm{NH}$ & $\mathrm{P}$ & MAPE WANN & MAPE NN \\
\hline 1 & 2 & $1.8919328 \%$ & $2.6419668 \%$ \\
\hline 2 & 2 & $1.8919328 \%$ & $2.4447918 \%$ \\
\hline 3 & 2 & $1.8919328 \%$ & $4.0309788 \%$ \\
\hline 4 & 2 & $1.8919328 \%$ & $2.4576868 \%$ \\
\hline 1 & 3 & $2.9932258 \%$ & $3.6277098 \%$ \\
\hline 2 & 3 & $2.9932258 \%$ & $5.5225828 \%$ \\
\hline 3 & 3 & $2.9932258 \%$ & $3.3162208 \%$ \\
\hline 4 & 3 & $2.9932258 \%$ & $7.5679428 \%$ \\
\hline 1 & 4 & $4.2723738 \%$ & $2.1618958 \%$ \\
\hline 2 & 4 & $4.2723738 \%$ & $4.1687428 \%$ \\
\hline 3 & 4 & $4.2723738 \%$ & $: 4.0560008 \%$ \\
\hline 4 & 4 & $4.2723738 \%$ & $3.0914318 \%$ \\
\hline
\end{tabular}

Pada kasus long term prediction, WANN maupun NN hanya mampu sampai prediksi data yang ke-3, setelah itu hasil prediksi data menuju ke suatu nilai yang sama sehingga hasil prediksi data sudah tidak layak digunakan. Hal ini disebabkan selisih dari prediktor terlalu kecil dan menuju ke suatu nilai 0 , sehingga hasil dari prediksi data menuju ke suatu nilai yang 


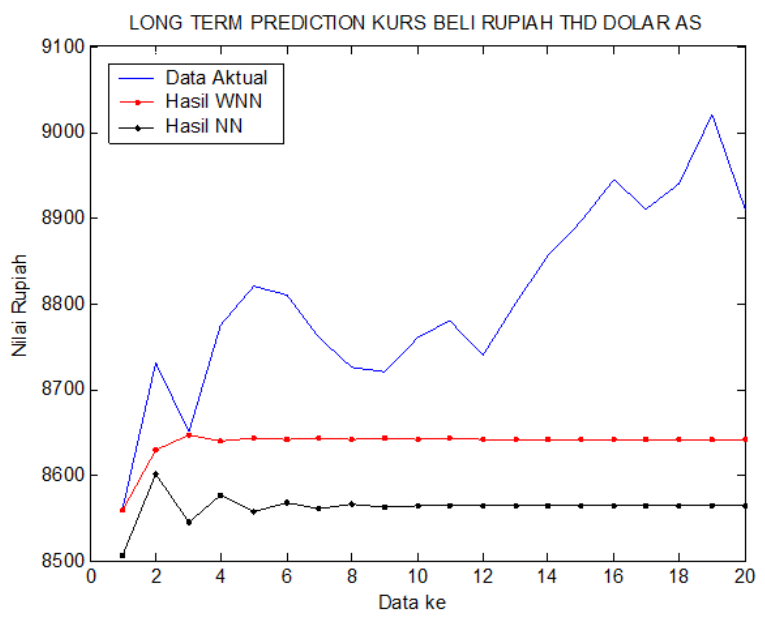

Gambar 5: Grafik Hasil Long Term Prediction $\mathrm{NH}=1$, Prediktor $=2$

sama yang terlihat pada Gambar 5 menunjukkan grafik hasil yang sudah tidak dapat ditoleransi.

\section{Kesimpulan dan Saran}

\subsection{Kesimpulan}

Dari hasil uji coba program yang telah dilakukan diperoleh kesimpulan :

a. Jumlah node pada neuron hidden tidak dapat meningkatkan performance jaringan WANN maupun Pre-NN.

b. Banyak prediktor yang digunakan mempengaruhi hasil prediksi data, semakin banyak prediktor hasil prediksi data semakin tidak akurat.

c. MAPE hasil dari prediksi data WANN lebih kecil dibandingkan dengan Pre-NN, dengan demikian hasil prediksi data WANN lebih baik dibandingkan dengan Pre-NN.

d. Prediksi data dengan WANN menghasilkan nilai MAPE yang sama sehingga dapat dikatakan metode ini stabil.

e. WANN maupun Pre-NN hanya mampu untuk prediksi data short term prediction. 


\subsection{Saran}

Untuk penelitian selanjutnya dapat dikaji banyak data minimal untuk training, pre-processing dengan menggunakan bentuk-bentuk wavelet yang lain misal, Coiflet Wavelets, Symlet Wavelets

\section{Pustaka}

[1] Burrus C. Sidney, DKK., Introduction to Wavelets and Wavelet Transforms, Prentice Hall International, Inc, Housto, 1998.

[2] Cryer, Jonatan D., time series Analysis, PWS-KENT Publishing company, Boston, 1996.

[3] Fausett Laurene, Fundamentals of Neural Network, Prentice Hall, New Jersey, 1994.

[4] Lin Feng, DKK, Times Series Forecasting with Neural Network, Central Queensland Universty, Australia, 1994.

[5] Loh Ruey Hwa, Times Series Forecast with neural network and wavelet techniques, The University of Queeland, 2003.

[6] Reanaud Oliver DKK, Kalman-type Filtering using the Wavelet Transform, Elsivier Science, 2000.

[7] Vlad SoRIN, On the prediction methods using neural network, University of Suceava, Romania, 2002.

[8] Zhang Zhguo, San ye, Adaptive Wavelet Neural Network for Prediction of Hourly NOx and NO2 Concentration. 